\title{
RAPID EYE: an Aid Memoir for Comprehensive Evaluation of Patient in Post-cardiac Surgery Recovery Unit
}

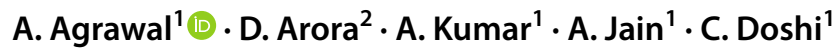

Received: 4 August 2021 / Accepted: 28 August 2021 / Published online: 8September 2021

(c) Association of Surgeons of India 2021

Over the last few years, tremendous advancement in information and technology has made it possible to disseminate enormous amount of medical information to healthcare providers as well as the general population. Often times, it is overwhelming for the young trainees to keep track of this glut of information. To prepare the next generation of physicians and surgeons, it is of utmost importance that trainees inculcate sound medical knowledge. It cannot be emphasized enough about the importance of a thorough and complete clinical assessment of patients in cardiac surgery intensive units to help make informed decisions. There are several mnemonics in medicine which assist clinicians to remember common causes of diseases and their differential diagnosis. Also mnemonics are quick checklist and can become part of daily progress report noted in the patient case file, for instance, FAST HUG (feeding, analgesia, sedation, thromboprophylaxis, head up 30 degrees, ulcer prophylaxis, glycemic control) mnemonic to improve the quality of care of critically ill patients in intensive care units (ICU) [1]. Furthermore, every individual critical care unit has its own remedial measures to improve patient care practices, and certainly mnemonics are one such essential tool. This mnemonic had further modified into FAST HUGS BID (feeding, analgesia, sedation, thromboprophylaxis, head up 30

A. Agrawal

vishnuagrawal3008@gmail.com

D. Arora

divyamlbjhs.arora@gmail.com

A. Kumar

drakshay82@gmail.com

A. Jain

aniljain78@gmail.com

C. Doshi

drchiragdoshi@yahoo.com

1 Department of CVTS, U N Mehta Institute of Cardiology \& Research Center, Ahmedabad, Gujarat, India

2 Holy Heart Hospital, Rohtak, Haryana, India degrees, ulcer prophylaxis, glycemic control, supplement $\mathrm{O}_{2}$, bowel, indwelling catheter, drugs/delirium) to make it more comprehensive, while others used this mnemonic for early recognition and treatment of ventilator-associated pneumonias $[2,3]$. The components of FAST HUGS BID were modified to recognize surgical issues earlier in patients where post-operative care was predominantly undertaken by anesthesiologists [4]. Also the components of FAST HUG mnemonic changed to cover nutritional support of their critically ill patients in ICU [5]. Likewise, the "GHOST CAP" (glucose, hemoglobin, oxygen, sodium, temperature, comfort, arterial blood pressure, acute changes in $\mathrm{PaCO}_{2}$ ) mnemonic is used in neurology ICU for the care of brain injury patients [6]. Another "FAST HUG MAIDENS" (feeding, analgesia, sedation, thromboprophylaxis, hyperactive or hypoactive delirium, stress ulcer prophylaxis, glucose control, medication, antibiotics, indications for medications, drug dosing, electrolytes, hematology and other laboratory results, no drug interaction, stop dates) was proposed to identify drug-related issues in ICU care [7].

Although this mnemonic is useful in the care of surgical patients, cardiac surgery units need elaborative and comprehensive survey at frequent intervals as they are under continuous monitoring, often utilizing invasive lines or catheters. Some commonly used mnemonics in cardiac surgery include "TAMPONADE" (thromboembolism, AV block, mismatch PPM, perivalvular leak, obstruction of coronary artery, neurological deficit, abscess, dysfunction of valve leaflets, endocarditis) for complications after AVR, "SKIRMISH" ( stroke, kidney failure, infection, rhythm disturbances, myocardial ischemia, inflammatory state, shock, hemorrhage) (https://www.google.com/search?q=cardiac+surgey+ mnemonics\&tbm=isch\&ved $=2$ ahUKEwj20fG_zK3yA hWQm0sFHdMrBjwQ2cCegQIABAA\&oq=cardiac+surgey+mnemonics\&gs_lcp=CgNpbWcQAzoICAAQgAQQ sQM6BQgAEIAEOgYIABAKEBhQ0acDWMfgA2Cx6gNo AHAAeACAAdMCiAGcEJIBCDAuMTUuMC 4xmAE AoAEBqgELZ3dzLXdpei1pbWfAAQE\&sclient=img\& 
Table 1 The mnemonic RAPID EYE

\begin{tabular}{|c|c|c|}
\hline & RAPID EYE & Parameters to be evaluated \\
\hline \multirow[t]{3}{*}{$\mathrm{R}$} & Rate & Tachycardia/bradycardia \\
\hline & Rhythm & Atrial/ventricular arrhythmia \\
\hline & Respiration & Chest expansion/ventilatory parameters \& flow volume graph \\
\hline \multirow[t]{3}{*}{ A } & ABG analysis & Acidosis/alkalosis \\
\hline & Abdomen & Bowel sound/distension \\
\hline & Auscultation & Cardiac/respiratory added sounds \\
\hline \multirow[t]{4}{*}{$\mathrm{P}$} & Pulses & All peripheral pulses \\
\hline & Peripheries & Cold/warm \\
\hline & Pressures & MAP, CVP, PAP \\
\hline & Plethysmography \& perfusion index & $\begin{array}{l}\text { Area under curve proportional to cardiac output and representative of vasodila- } \\
\text { tion/vasoconstriction }\end{array}$ \\
\hline \multirow[t]{3}{*}{ I } & Investigations \& imaging & Hematological/biochemistry/radiological (X-ray/USG) \\
\hline & Inotropes & Inotropic score \\
\hline & Incision sites & Sign of inflammation/wound gap/discharge \\
\hline \multirow[t]{2}{*}{$\mathrm{D}$} & Drugs & Antibiotics, anti-arrhythmic, anticoagulant, antiplatelets, analgesics, and antacids \\
\hline & Drains & $\begin{array}{l}\text { High drain output, re-exploration likely } \\
\text { Low drain output, drain removal }\end{array}$ \\
\hline \multirow[t]{3}{*}{$\mathrm{E}$} & Euvolemia & Even balance (impending AKI), negative balance (low EF) \\
\hline & Euglycemia & Target below 180 \\
\hline & Electrolytes & Hypo-/hyperkalemia, hypo-/hypernatremia, hypomagnesemia \\
\hline Y & Yesterday's issue & Resolving or progressing \\
\hline \multirow[t]{2}{*}{$\mathrm{E}$} & 12 lead ECG & Changes if present compare to preoperative \\
\hline & $2 \mathrm{D}$ echo & Effusions/clot/residual lesions/biventricular function \\
\hline
\end{tabular}

Abbreviations: $A B G$, arterial blood gas; $M A P$, mean arterial pressure; $C V P$, central venous pressure; $P A P$, pulmonary artery pressure; $E C G$, electrocardiogram

ei=nC8WYfaTGZC3rtoP09eY4AM\&bih=821\&biw=1280) for major complications after cardiac surgery, and "I NEED HELP" (inotropes, NYHA class/natriuretic peptides, endorgan dysfunction, ejection fraction, defibrillator shocks, hospitalizations, edema/escalating diuretics, low blood pressure, prognostic medication) for timely referral of heart failure patients [8]. Here, we apprise the mnemonic RAPID EYE (Table 1) which helped our trainee residents as well as on duty staff immensely to make comprehensive assessment of our cardiac surgery patients.

In our experience we found this mnemonic very useful as it includes clinical, laboratory, and radiological investigations. It helps in real-time assessment of the patient's condition as well direction in which it is progressing. Also for resident doctors and nursing care staff, it's easy to remember and help them to detect problems earlier. In our experience, we have found that inculcating this mnemonic in our daily patient care, we have been able to identify near-misses, proactively diagnose and treat post-operative complications, and thereby improve quality of cardiac surgery intensive care outcomes. In our opinion, this is one of the few comprehensive mnemonic in cardiac surgery intensive care units which has not been previously described or discussed in literature. Although it is a very useful and comprehensive tool in ICU care, it is not a substitute for a comprehensive and multi-disciplinary team-based approach of managing post-operative critically ill patients.

\section{Declarations}

Conflict of interest We confirm that:

There has not been any duplicate publication or submission elsewhere. All authors have read and approved the manuscript. All authors will sign an exclusive license to publish. There is no ethical problem or conflict of interest.

\section{References}

1. Vincent JL (2005) Give your patient a fast hug (at least) once a day. Crit Care Med 33:1225-1229

2. Vincent WR 3rd, Hatton KW (2009) Critically ill patients need "FAST HUGS BID" (an updated mnemonic). Crit Care Med 37:2326-2327

3. Papadimos TJ, Hensley SJ, Duggan JM, Khuder SA, Borst MJ, Fath JJ et al (2008) Implementation of the "FASTHUG" concept decreases the incidence of ventilator-associated pneumonia in a surgical Intensive Care Unit. Patient Saf Surg 2:3 
4. Nair AS, Naik VM, Rayani BK (2017) FAST HUGS BID: modified mnemonic for surgical patient. Indian J Crit Care Med 21:713-714

5. Monares Zepeda E, Galindo Martín CA (2015) Giving a nutritional fast hug in the intensive care unit. Nutr Hosp 31:2212-2219

6. Taccone FS, De Oliveira Manoel AL, Robba C et al (2020) Use a "GHOST-CAP" in acute brain injury. Crit Care 24:89

7. Mabasa VH, Malyuk DL, Weatherby EM, Chan A (2011) A standardized, structured approach to identifying drug-related problems in the intensive care unit: FASTHUG-MAIDENS. Can J Hosp Pharm 64:366-369
8. Baumwol J (2017) "I need help"-a mnemonic to aid timely referral in advanced heart failure. J Heart Lung Transplant 36:593-594. https://doi.org/10.1016/j.healun.2017.02.010 (Epub 2017 Feb 10 PMID: 28258792)

Publisher's Note Springer Nature remains neutral with regard to jurisdictional claims in published maps and institutional affiliations. 